\title{
Near UV-Blue Excitable Green-Emitting Nanocrystalline Oxide
}

\author{
C. E. Rodríguez-García, ${ }^{1}$ N. Perea-López, ${ }^{2}$ and G. A. Hirata ${ }^{3}$ \\ ${ }^{1}$ Programa de Posgrado en Física de Materiales, CICESE-UNAM, Carretera Ensenada-Tijuana No. 3918, Zona Playitas, C.P. 22860, \\ Ensenada, BC, Mexico \\ ${ }^{2}$ Laboratorio de Investigaciones en Nanociencias y Nanotecnología (LINAN) y División de Materiales Avanzados, \\ IPICYT, Camino a la Presa San José 2055, Lomas 4a. Sección, San Luis Potosí 78216, Mexico \\ ${ }^{3}$ Centro de Nanociencias y Nanotecnología Universidad Nacional Autonóma de México, Km 107 Carretera Tijuana-Ensenada, \\ 22800 Ensenada, BC, Mexico
}

Correspondence should be addressed to G. A. Hirata, hirata@cnyn.unam.mx

Received 1 October 2010; Accepted 4 April 2011

Academic Editor: Peter Majewski

Copyright $\odot 2011$ C. E. Rodríguez-García et al. This is an open access article distributed under the Creative Commons Attribution License, which permits unrestricted use, distribution, and reproduction in any medium, provided the original work is properly cited.

Green-emitting Eu-activated powders were produced by a two-stage method consisting of pressure-assisted combustion synthesis and postannealing in ammonia. The as-synthesized powders exhibited a red photoluminescence (PL) peak located at $\lambda=616 \mathrm{~nm}$ when excited with $\lambda=395 \mathrm{~nm}$ UV. This emission peak corresponds to the ${ }^{5} \mathrm{D}_{0} \rightarrow{ }^{7} \mathrm{~F}_{2}$ transition in Eu ${ }^{3+}$. After annealing in ammonia, the PL emission changed to an intense broad-band peak centered at $\lambda=500 \mathrm{~nm}$, most likely produced by $4 \mathrm{f}^{6} 5 \mathrm{~d}^{1} \rightarrow 4 \mathrm{f}^{7}$ electronic transitions in $\mathrm{Eu}^{2+}$. This green-emitting phosphor has excitation band in the near UV-blue region $(\lambda=300-450 \mathrm{~nm})$. Xray diffraction analysis reveals mainly the orthorhombic EuAlO $\mathrm{Al}_{3}$ and $\mathrm{Al}_{2} \mathrm{O}_{3}$ phases. Transmission electron microscopy observations showed that the grains are formed by faceted nanocrystals $(\sim 4 \mathrm{~nm})$ of polygonal shape. The excellent excitation and emission properties make these powders very promising to be used as phosphors in UV solid-state diodes coupled to activate white-emitting lamps.

\section{Introduction}

Commercial white-light-emitting diodes (WLEDs) are composed of a blue-GaN chip which pumps YAG: $\mathrm{Ce}^{3+}$ yellow phosphor, and the blend of these two colors, the transmitted blue and luminescent yellow, results in white-light emission [1]. However, WLEDs fabricated in this way deliver di-chromatic white-light with poor color-rendering index quality $(\mathrm{CRI} \sim 75)$ [2]. To solve this problem, WLEDs should be composed of blue, green, and red-emitting multiphase phosphors excited by a UV-blue $(\lambda=365-450 \mathrm{~nm})$ InGaN chip [3]. This type of WLED is advantageous because the white color is generated by phosphors and this produces an excellent color-rendering index (CRI 95) [3-5]. Based on the above, research in material science engineering has focused on the production of efficient green phosphors, considering that these can be combined with either the blue component from the InGaN chip or with one supplied by another phosphor, to produce artificial white-light with high CRI. Phosphors constituted by nanocrystalline and submicrocrystalline oxides doped with rare earths (REs) are advantageous because they have high chemical and thermal stability [6]. Another valuable property of the nanocrystalline oxide phosphors is their large surface area, which enhances luminescence intensity [7]. In addition, RE-doped oxides allow a wide range of technological applications.

Europium aluminates $\mathrm{EuAlO}_{3}$ and $\mathrm{EuAlO}_{3}: \mathrm{Eu}^{2+}[8-10]$ which have been studied for their interesting luminescent properties applied to solid-state lighting. The precursors of $\mathrm{EuAlO}_{3}$ and $\mathrm{EuAlO}_{3}: \mathrm{Eu}^{2+}$ are $\mathrm{Al}_{2} \mathrm{O}_{3}: \mathrm{Eu}^{3+}$ and $\mathrm{Al}_{2} \mathrm{O}_{3}: \mathrm{Eu}^{2+}$, respectively [8]. Ozuna et al. [11] reported two compounds, $\alpha-\mathrm{Al}_{2} \mathrm{O}_{3}: \mathrm{Eu}^{3+}$ and $\gamma-\mathrm{Al}_{2} \mathrm{O}_{3}: \mathrm{Eu}^{3+}$ as candidates for the red component and specified that low concentration of europium $(x=1.0-5.0$ at \%) is required in order to obtain intense red emission. In addition, when the Eu-doping concentration $x \geq 10.0$ at $\%$, it produces $\mathrm{EuAlO}_{3}[8]$. Few reports have referred to the $\mathrm{Al}_{2} \mathrm{O}_{3}: \mathrm{Eu}^{2+}$ system [12] which produces green emission.

$\mathrm{EuAlO}_{3}$ crystallizes in the distorted orthorhombic perovskite structure with general chemical formula $\mathrm{ABO}_{3}$ [13]. 
The large A ion has 12-fold and the smaller B ion 6-fold coordination in the crystalline lattice. In this case the $\mathrm{Eu}^{3+}$ is at the A-site of $\mathrm{EuAlO}_{3}$. When $\mathrm{Eu}^{3+}$ is reduced to $\mathrm{Eu}^{2+}$, it remains at the A-site producing defects in the lattice. The role of these defects and RE impurities is important to explain the red and green emissions of europium aluminates in powder form $[8,13]$. However, the $\mathrm{f}-\mathrm{f}$ forbidden transitions in $\mathrm{Eu}^{3+}$ are very sensitive towards the crystal-field environment in the host lattice $[14,15]$. If the $\mathrm{Eu}^{3+}$ site is noninversion symmetry site, the ${ }^{5} \mathrm{D}_{0} \rightarrow{ }^{7} \mathrm{~F}_{2}(\lambda=616 \mathrm{~nm})$ electric-forced dipole transition is more probable [15]. This also means that if the crystal-field in the lattice is distorted, a forced electric dipole transition is promoted. The Goldsmith tolerance factor describes the stability of the perovskite structure, $\mathrm{ABO}_{3}$, and is defined as $t=\left(r_{A}+r_{O}\right) / \sqrt{ } 2\left(r_{B}+r_{O}\right)$, where $r_{A}, r_{B}$, and $r_{O}$ are the 2 average ionic radii of the $A-, B$-site cations and of the $\mathrm{O}^{2-}$ ion, respectively [16]. By means of the Goldsmith factor $(t)$, it is possible to determine the distortion of the perovskite structure, that is an ideal perovskite structure has a $t=1$, and if this value is reduced, the distortion of the perovskite increases. For the ionic radii of $\mathrm{Eu}^{3+}=1.07 \AA$, $\mathrm{Al}^{3+}=0.54 \AA$, and $\mathrm{O}^{2-}=1.4 \AA$, the Goldsmith factor $(t)$ for the $\mathrm{EuAlO}_{3}$ structure is $t=0.90$. In this sense, EuAlO shows a certain degree of distortion, hence the red emission due to the ${ }^{5} \mathrm{D}_{0} \rightarrow{ }^{7} \mathrm{~F}_{2}$ transition is now possible. The $\mathrm{Eu}^{2+}=$ $1.31 \AA, t=0.98$, and $\mathrm{EuAlO}_{3}: \mathrm{Eu}^{2+}$ have a structure very close to the ideal perovskite.

In a previous report of our group, combustion synthesis plus postannealing was applied to produce $\mathrm{EuAlO}_{3}$ and $\mathrm{EuAlO}_{3}: \mathrm{Eu}^{2+}[8]$. However, the pressure-assisted combustion synthesis method has not been explored to produce these materials. In this context, the pressure effects on other europium aluminates, as well as on different materials, are an important factor that determines the nanostructured morphology [17].

In the present study, green phosphors were produced by means of pressure-assisted combustion synthesis (PACS) plus the rapid IN and rapid OUT (RIRO) process [8]. As a final result, we obtained luminescent nanocrystalline powders with intense green emission due to their content of $\mathrm{Eu}^{2+}$ ions.

\section{Experimental Section}

2.1. PACS Method. Nanocrystalline green-emitting powders were prepared in two stages. In stage 1, we applied the pressure-assisted combustion synthesis (PACS) method [18] as follows: the metal nitrates, europium nitrate $\left[\mathrm{Eu}\left(\mathrm{NO}_{3}\right)_{3} \cdot 6 \mathrm{H}_{2} \mathrm{O}\right.$ reacton $\left.99.9 \%\right]$ and aluminum nitrate $\left[\mathrm{Al}\left(\mathrm{NO}_{3}\right)_{3} \cdot \mathrm{H}_{2} \mathrm{O}\right.$ Puratronic $\left.99.9965 \%\right]$ were dissolved in $25 \mathrm{ml}$ of deionized water in a quartz beaker, and hydrazine $\left[\mathrm{N}_{2} \mathrm{H}_{4}\right.$ Alfa AEesar 98.5\%] was added as a reductive freecarbon fuel to prevent contamination, forming a gelatinous homogeneous blend. The quartz beaker containing the blend was placed into a closed reactor. A flux of $50 \mathrm{sccm}$ of argon (Ar) was established in order to create an inert atmosphere and temperature. Subsequently, the reactor temperature was increased from room temperature to $100^{\circ} \mathrm{C}$ and maintained for $15 \mathrm{~min}$ to expel water vapor. The exhaust valve was closed, allowing flowing Ar to pressurize the reactor to 2.75 MPa. The temperature of the reactor was gradually increased to $340^{\circ} \mathrm{C}$. The pressure inside the reactor also increased progressively, and the hydrazine was ignited in the range of $190-280^{\circ} \mathrm{C}$ showing a peak in pressure. The final pressure value inside the reactor was $6 \mathrm{MPa}$. Subsequently, the exhaust valve was opened to release the pressure and give vent to residual vapors. A weaker argon flux $(10 \mathrm{sccm})$ was maintained for approximately $3 \mathrm{~h}$ to allow a decrease in temperature. The chemical precursors were adjusted to different Eu concentration of $x=1.5,5.0,10.0$, or 15.0 at \%. As a result of this stage, as-synthesized red phosphor powder samples were obtained.

2.2. RIRO Process. Reducing atmospheres of $\mathrm{H}_{2}, \mathrm{~N}_{2} / \mathrm{H}_{2}$, $\mathrm{NH}_{3}$, or their combinations have been used elsewhere to convert the $\mathrm{Eu}^{3+}$ into $\mathrm{Eu}^{2+}[8,17]$. In these studies, the phosphor powder was rapidly introduced and pulled out in a preheated tubular furnace with flowing $\mathrm{NH}_{3}$ at $1100^{\circ} \mathrm{C}$. This process is also called the rapid IN and rapid OUT process (RIRO) and is well-described elsewhere [8].

In stage 2 of the present study, the powders obtained by PACS (in stage 1) were placed in a quartz crucible inside a tubular furnace and heated at a temperature of $1100^{\circ} \mathrm{C}$ under constant flow (flow rate $=40 \mathrm{sccm}$ ) of ultra-highpurity ammonia (99.99\% $\mathrm{NH}_{3}$ analytical grade). The RIRO technique was applied during 45 minutes at $1100^{\circ} \mathrm{C}$. As a result of stage 2, we obtained luminescent powders of $\mathrm{EuAlO}_{3}: \mathrm{Eu}^{2+}$ with brilliant green emission.

2.3. Characterization. The X-ray diffractograms of the powders were obtained with a Philips X'pert diffractometer with $\mathrm{CuK}_{\alpha}$ radiation $(\lambda=0.15406 \mathrm{~nm})$. Measurements in a $2 \theta=$ $20-80^{\circ}$ range were taken with a step size of $0.02^{\circ}$ and a $1 \mathrm{sec}$ dwell per point. Scanning electron microscopy (SEM) images were captured with a JEOL electron microscope Model JSM5300. Transmission electron microscopy (TEM) images were obtained with a JEOL-2010 operated at $200 \mathrm{kV}$ accelerating voltage. Photoluminescence (PL) spectra were collected with a fluorescence spectrophotometer (Hitachi FL-4500). All measurements were performed at room temperature.

\section{Results and Discussion}

3.1. XRD Analysis. Figure 1(a) shows the comparison of the XRD patterns of $\mathrm{EuAlO}_{3}$ powder samples produced by PACS (stage 1) for the different Eu concentrations. The XRD patterns of the samples with concentrations of 1.5 and 5.0 at $\% \mathrm{Eu}$ were dominated by the mixture of the $\alpha$ $\mathrm{Al}_{2} \mathrm{O}_{3}$ and $\gamma-\mathrm{Al}_{2} \mathrm{O}_{3}$ as reported elsewhere [11]. The residual phase of $\mathrm{AlOOH}$ also appeared and is labeled with the " $*$ " symbol. This phase is attributed to the low temperature range $\left(100-340^{\circ} \mathrm{C}\right)$ in which $\mathrm{AlOOH}$ formation occurs [19]. At the higher Eu concentrations of 10.0 and 15.0 at \% the product contained mainly the orthorhombic phase $(\mathrm{O})$, which corresponds to $\mathrm{EuAlO}_{3}$. However, the 10.0 at \% Eudoped sample showed reflection peaks which correspond to 


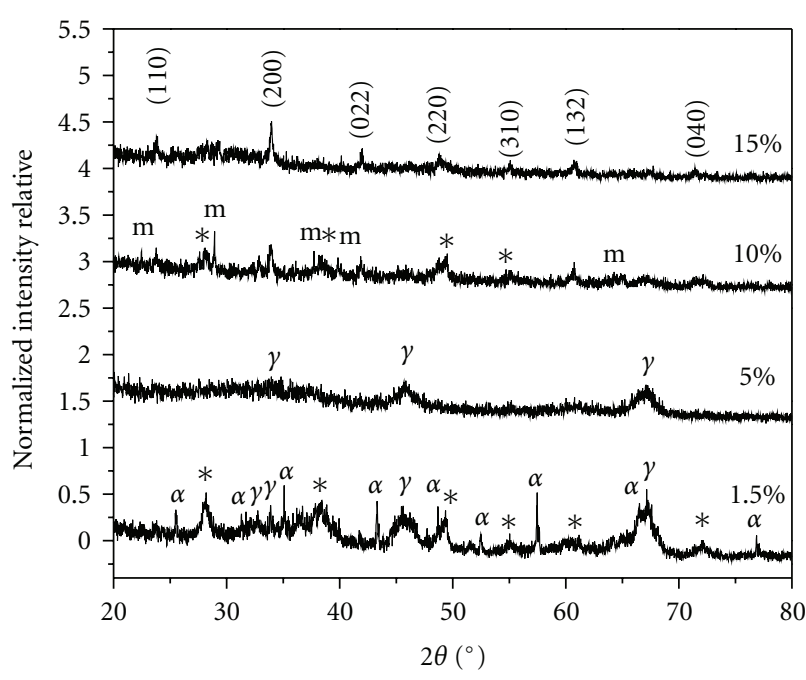

(a)

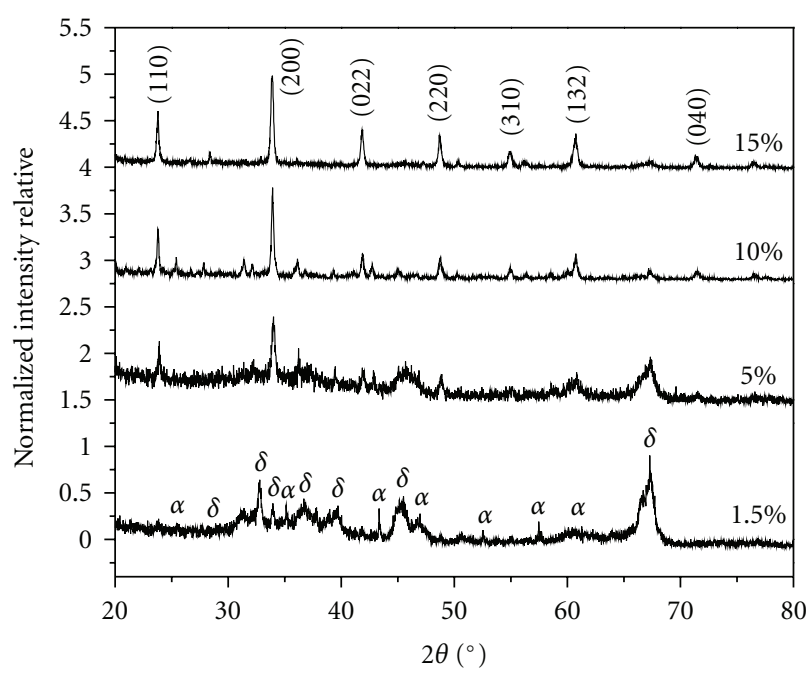

(b)

FIGURE 1: (a) XRD patterns of the as-synthesized red-emitting phosphor powders produced by the PACS method. Principal peaks are labeled and correspond to the crystalline phases: $(\alpha) \alpha-\mathrm{Al}_{2} \mathrm{O}_{3}$ (JCPDS \#50-1496), ( $\gamma) \gamma-\mathrm{Al}_{2} \mathrm{O}_{3}$ (JCPDS \#10-0425), (*) $\mathrm{AlOOH}$ (JCPDS \#21-1307). Peaks of the 10.0 at \% Eu-doped sample are labeled with "m" (JCPDS \#72-0683). Below, (b) XRD patterns of the green-emitting phosphor powders produced after RIRO. Principal peaks are labeled and correspond to the crystalline phases: $(\alpha) \alpha$ $\mathrm{Al}_{2} \mathrm{O}_{3}$ (JCPDS \#50-1496) and $(\delta) \delta-\mathrm{Al}_{2} \mathrm{O}_{3}$ (JCPDS \#46-1131). The principal planes of the orthorombic $\mathrm{EuAlO}_{3}$ (JCPDS \#09-0084) phase are indexed in both cases.

the $\mathrm{Eu}_{4} \mathrm{Al}_{2} \mathrm{O}_{9}$ monoclinic phase and are labeled with $(\mathrm{m})$ in the XRD pattern. The principal planes of the orthorhombic phase $\left(\mathrm{EuAlO}_{3}\right)$ are indexed in the XRD pattern of the powder sample doped with 15.0 at $\%$.

Regarding the phosphor powder, samples produced by RIRO (stage 2), XRD analysis of the sample containing 1.5 at $\%$ was dominated by the $\alpha-\mathrm{Al}_{2} \mathrm{O}_{3}$ and $\delta-\mathrm{Al}_{2} \mathrm{O}_{3}$ phases (see Figure $1(\mathrm{~b}))$. At 5.0 at \%, the Eu-doped sample presented the

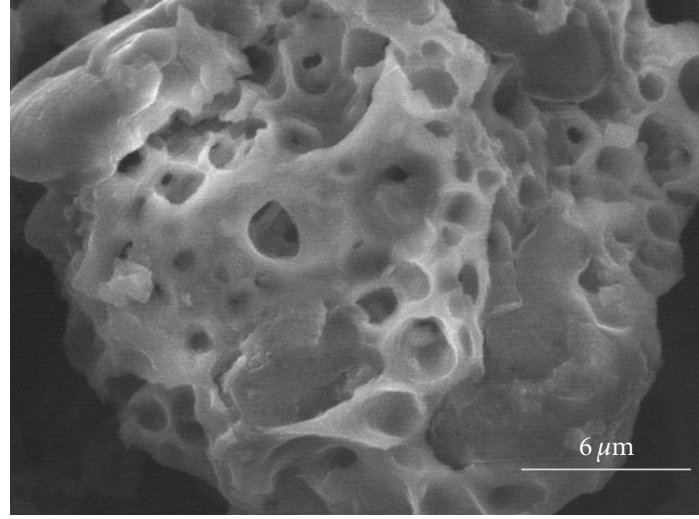

FIGURE 2: SEM image of the red-emitting porous powder $(x=10.0$ at $\% \mathrm{Eu}$ ) produced by PACS performed at $200 \mathrm{kV}$.

appearance of the orthorhombic phase. For the 10.0 at \% Eudoped sample, the formation of the orthorhombic $\mathrm{EuAlO}_{3}$ with small traces of $\alpha-\mathrm{Al}_{2} \mathrm{O}_{3}$ was mainly detected. At the highest Eu concentration (15.0 at \%), it was clearly noticed that the $\alpha-\mathrm{Al}_{2} \mathrm{O}_{3}$ and $\delta-\mathrm{Al}_{2} \mathrm{O}_{3}$ phases were absent since only reflections corresponding to $\mathrm{EuAlO}_{3}$ appeared in the XRD pattern. Table 1 summarizes the powder crystalline phases produced by PACS and RIRO and shows the temperature and pressure values of the PACS reaction peaks. These results are in agreement with a previous report [8], which states that the orthorhombic phase depends on Eu-doping concentration.

3.2. SEM Analysis. Figure 2 shows a representative SEM image corresponding to the 10.0 at \% Eu-doped phosphor produced by PACS. The morphology of this sample reveals a large number of irregular pores of sizes in the range of $1.0-3.0 \mu \mathrm{m}$. This high porosity increases the amount of grain surface area which probably causes the enhancement of luminescence intensity of the 10.0 at \% Eu-doped sample. Other studies have correlated porosity with the enhancement of optical properties [20]. However, the relation between porosity and luminescence intensity is still under study.

3.3. TEM Characterization. Figure 3 shows a TEM micrograph of faceted nanocrystals of irregular polygonal shape of the 10.0 at \% Eu-doped green-emitting powders obtained by RIRO. Mean size of the nanocrystals is $\sim 4 \mathrm{~nm}$. The nanocrystalline nature of the 10.0 at \% Eu-doped sample increases the amount of surface area; both features of this sample are correlated with luminescence enhancement.

3.4. Photoluminescence Analysis. The ( $x=1.5-15.0$ at \%) powders produced by PACS showed red emissions under long-UV excitation. Figure 4(a) illustrates the PL excitation spectra obtained with fixed emission at $616 \mathrm{~nm}$. The weak broad excitation band centered at $275 \mathrm{~nm}$ is attributed to the well-known Eu-O charge-transfer transition [21]. The spectra show narrow excitation lines at longer wavelengths corresponding to the characteristic $\mathrm{f} \rightarrow \mathrm{f}$ transitions of $\mathrm{Eu}^{3+}$. These lines are spectroscopically assigned as follows: 
TABle 1: Summary of crystalline phases obtained in both stages. Stage 1: PACS method. Stage 2: RIRO technique at $1100^{\circ} \mathrm{C}$. The third column shows the pressure and reaction temperature parameters observed in PACS.

\begin{tabular}{lccc}
\hline Eu-doping concentration (at) & XRD phases (PACS) & XRD phases (RIRO) & T( $\left.{ }^{\circ} \mathrm{C}\right), \mathrm{P}(\mathrm{MPa})$ in PACS \\
\hline $1.5 \%$ & $\alpha+\gamma+*$ & $\alpha+\delta$ & $215,3.4$ \\
$5 \%$ & $\gamma$ & $\delta+O$ & $190,3.1$ \\
$10 \%$ & $O+*+m$ & $\delta+O$ & $280,5.0$ \\
$15 \%$ & $O$ & $O$ & $210,3.0$ \\
\hline
\end{tabular}

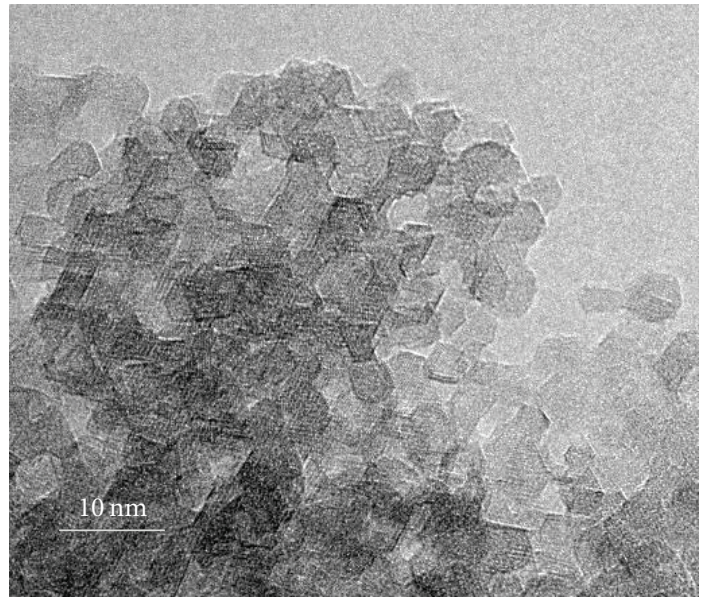

FIGURE 3: TEM image of the faceted nanocrystals observed in the green-emitting phosphor ( $x=10.0$ at $\% \mathrm{Eu})$ powder produced by RIRO.

${ }^{7} \mathrm{~F}_{0} \rightarrow{ }^{5} \mathrm{H}_{6}(318 \mathrm{~nm}),{ }^{7} \mathrm{~F}_{0} \rightarrow{ }^{5} \mathrm{D}_{4}(362 \mathrm{~nm}),{ }^{7} \mathrm{~F}_{0} \rightarrow{ }^{5} \mathrm{G}_{4}$ $(381 \mathrm{~nm})$, the strongest excitation line ${ }^{7} \mathrm{~F}_{0} \rightarrow{ }^{5} \mathrm{~L}_{6}(395 \mathrm{~nm})$, and, lastly, ${ }^{7} \mathrm{~F}_{1} \rightarrow{ }^{5} \mathrm{D}_{3}(416 \mathrm{~nm})[15,21]$.

Figure 4(b) shows the PL emission spectra of the powders produced by PACS with different Eu concentrations. The strongest contributions to the red emission come from the $\mathrm{Eu}^{3+}$ ions, mainly from the hypersensitive ${ }^{5} \mathrm{D}_{0} \rightarrow{ }^{7} \mathrm{~F}_{2}$ $(616 \mathrm{~nm})$ transition forced by an electric dipole mechanism; of less intensity is a single peak located at $592 \mathrm{~nm}$ due to the ${ }^{5} \mathrm{D}_{0} \rightarrow{ }^{7} \mathrm{~F}_{1}$ magnetic dipole. PL emission spectra of red-emitting powders were obtained under $\lambda=395 \mathrm{~nm}$ excitation wavelength. If the forced electric dipole transition $\left({ }^{5} \mathrm{D}_{0} \rightarrow{ }^{7} \mathrm{~F}_{2}\right)$ is more intense than the magnetic dipole $\left({ }^{5} \mathrm{D}_{0} \rightarrow{ }^{7} \mathrm{~F}_{1}\right)$, the $\mathrm{Eu}^{3+}$ is localized in a noninversion symmetry site within the crystal lattice [15]. Therefore, the $\left({ }^{5} \mathrm{D}_{0} \rightarrow{ }^{7} \mathrm{~F}_{2}\right) /\left({ }^{5} \mathrm{D}_{0} \rightarrow{ }^{7} \mathrm{~F}_{1}\right)$ intensity ratio, also called the asymmetry ratio, provides a measure of the degree of distortion of the inversion symmetry of the local $\mathrm{Eu}^{3+}$ ion in the lattice [22]. A plot of the ratio values of $\left({ }^{5} \mathrm{D}_{0} \rightarrow\right.$ $\left.{ }^{7} \mathrm{~F}_{2}\right) /\left({ }^{5} \mathrm{D}_{0} \rightarrow{ }^{7} \mathrm{~F}_{1}\right)$ calculated from the emission spectra is shown in the inset of Figure 4(b). It is important to note that the highest asymmetry ratio was obtained for the 10.0 at $\% \mathrm{Eu}$ concentration value of the asymmetry ratio. This high value in the asymmetry ratio is indicative of low-symmetry crystal-fields around the $\mathrm{Eu}^{3+}$ sites [23]. Consequently, the 10.0 at \% Eu-doped sample yields the highest luminescent intensity produced by the electric dipole ${ }^{5} \mathrm{D}_{0} \rightarrow{ }^{7} \mathrm{~F}_{2}$ transition. Additionally, its high-intensity red emission was about 13 times higher in comparison with the 1.5 and 5.0 at \% doped samples. Furthermore, it was 7 times more intense than the 15.0 at \% Eu-doped sample. The 10.0 at \% Eu-doped sample contained a mixture of a larger quantity of the orthorhombic $\mathrm{EuAlO}_{3}$ and less amount of the monoclinic $\mathrm{Eu}_{4} \mathrm{Al}_{2} \mathrm{O}_{9}$ crystalline phases. Red emission of the powder samples is mainly due to the ${ }^{5} \mathrm{D}_{0} \rightarrow{ }^{7} \mathrm{~F}_{2}$ transition. The hypersensitive ${ }^{5} \mathrm{D}_{0} \rightarrow{ }^{7} \mathrm{~F}_{2}$ transition occurs only if the crystal-field of the lattice is distorted and, as a consequence, the $\mathrm{Eu}^{3+}$ site of the ion is nonsymmetric [15]. In the case of $\mathrm{EuAlO}_{3}$, the $\mathrm{Eu}^{3+}$ ion can emit because the nature of the structure is distorted; in fact, it is called distorted perovskite [8].

After RIRO, the phosphor powders showed intense green emission under long-UV excitation. Figure 4(c) compares the excitation spectra of all powder samples, monitoring the maximum emission wavelength $(\lambda=500 \mathrm{~nm})$. The maximum excitation bands for the 10.0 at $\%$ and the 5.0 at $\%$ Eu-doped samples were centered at $\lambda=398 \mathrm{~nm}$, while for other concentrations the excitation peaks were centered at $\lambda=352 \mathrm{~nm}(1.5 \%$ at $)$ and $\lambda=370 \mathrm{~nm}(15.0$ at \%). The energy transfer from the host lattice to the $\mathrm{Eu}^{2+}$ sites was probably enhanced by the porous structure of the material. Figure 4(d) shows comparative emission spectra of the powder samples after RIRO. A strong broadband emission centered at $\lambda=500 \mathrm{~nm}$ was observed for the 10.0 at \% Eu-doped sample, while for the rest of the samples $(1.5,5.0$, and 15.0 at \%) showed reduced emission after the treatment in heated ammonia (RIRO process). The excitation wavelength light was fixed at $\lambda=398 \mathrm{~nm}$ for all the powder samples. The luminescent intensity of the 10.0 at \% Eu-doped sample was approximately 25-times higher compared with the rest of the samples. No characteristic $\mathrm{Eu}^{3+}$ transitions were detected in any of these samples and the broadband emission centered at $500 \mathrm{~nm}$ was associated to the $4 \mathrm{f}^{6} 5 \mathrm{~d}^{1}-4 \mathrm{f}^{7}$ electronic transitions of $\mathrm{Eu}^{2+}$ ions. This is an indication that the $\mathrm{Eu}^{3+}$ to $\mathrm{Eu}^{2+}$ reduction process was successful. The broadband character of the $\mathrm{Eu}^{2+}$ emission is due to the nature of the electronic transitions: differing from $4 \mathrm{f}-4 \mathrm{f}$ forced electric dipole transition in $\mathrm{Eu}^{3+}, 4 \mathrm{f}-5 \mathrm{~d}$ transitions of $\mathrm{Eu}^{2+}$ are allowed electric dipole and the excited states of the $5 \mathrm{~d}$ band are not strongly shielded from the crystal-fields by the $5 s^{2}$ and $5 p^{6}$ bands. As a consequence, the $5 \mathrm{~d}$ wave function is largely extended [15].

Red phosphor powders dominated by the $\mathrm{EuAlO}_{3}$ distorted phase were found to possess a highly porous structure. The porosity produced by PACS in the 10.0 at \% Eu-doped sample and preserved after RIRO treatment was induced by the pressure effect and temperature inside the reactor 


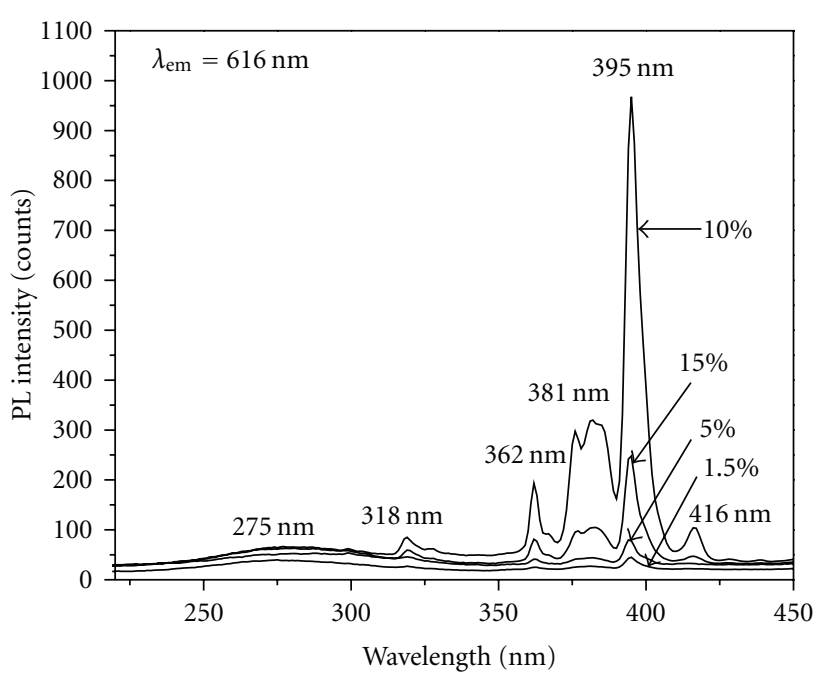

(a)

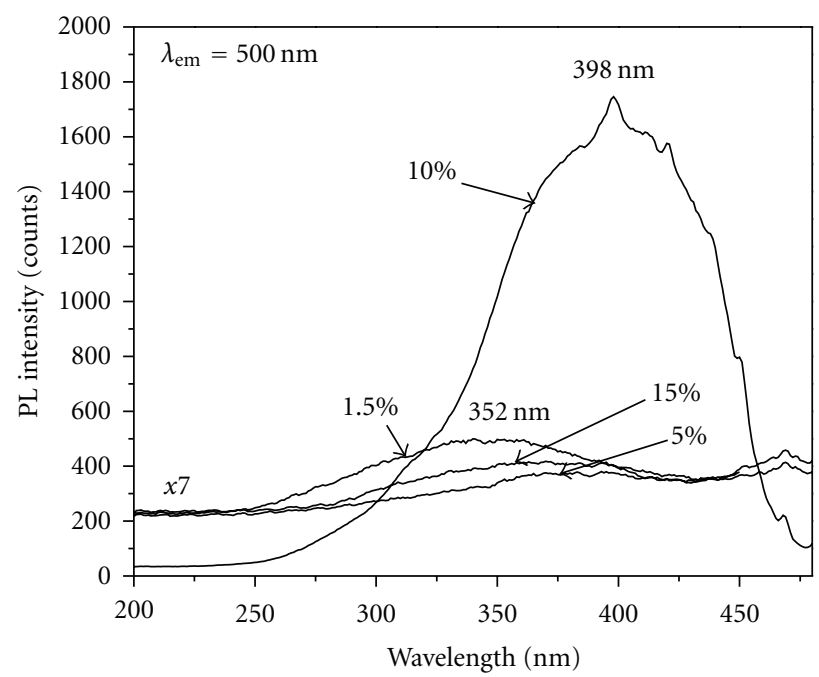

(c)

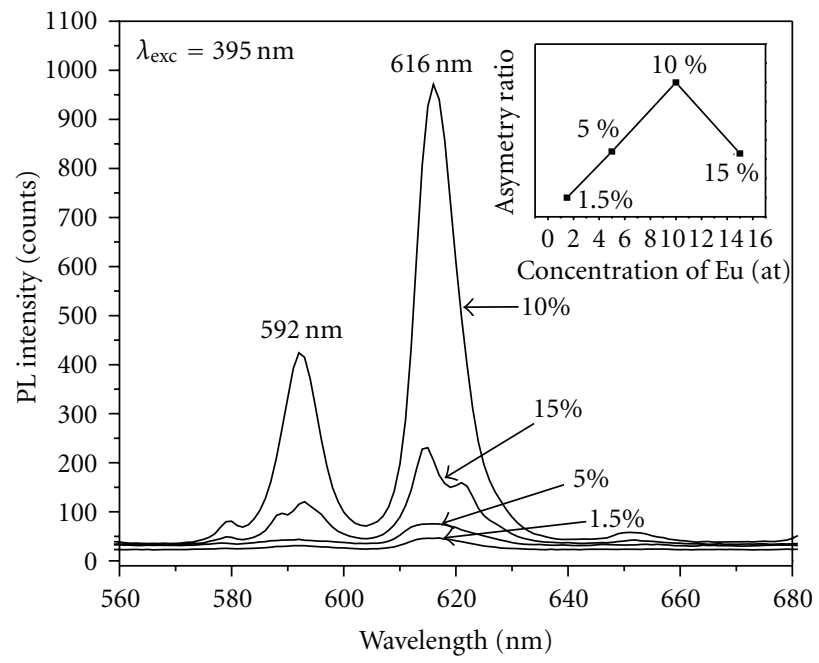

(b)

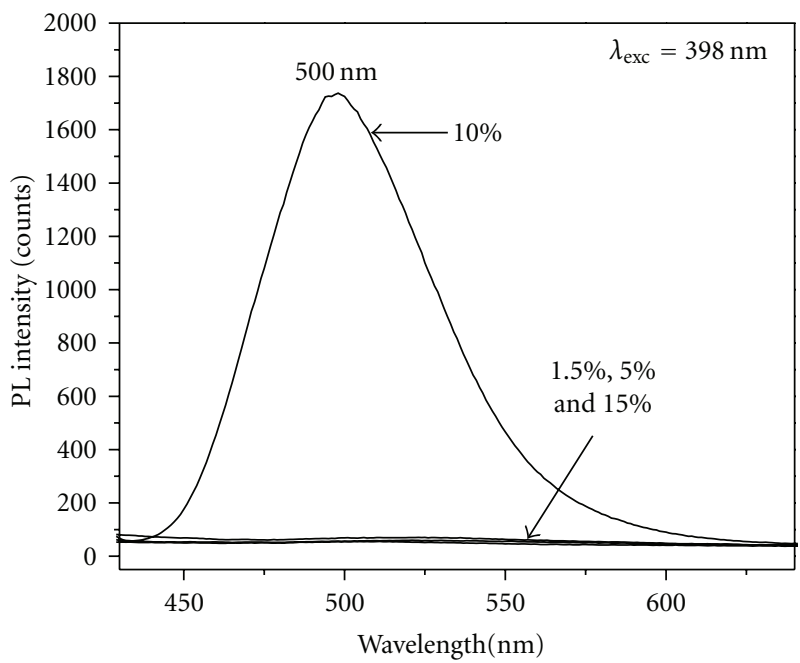

(d)

Figure 4: PL spectra of luminescent powders, $x=1.5-15.0$ at $\%$ Eu, produced by PACS: (a) excitation spectra for all Eu-doping concentrations at fixed $\lambda_{\mathrm{em}}=616 \mathrm{~nm}$ (red) and (b) emission spectra for all powders excited with $\lambda_{\text {exc }}=395 \mathrm{~nm}$. The inset shows the highest asymmetry ratio value at 10.0 at \% Eu-doping concentration. All measurements performed at room temperature. After RIRO: (c) excitation spectra for all Eu-doping concentrations at fixed $\lambda_{\mathrm{em}}=500 \mathrm{~nm}$ (green) and (d) emission spectra for all powders excited with $\lambda_{\text {exc }}=398 \mathrm{~nm}$.

during synthesis. Future studies need to test if there is a direct relation between the high luminescence intensity and the porosity of this material [20]. The gelatinous blend of nitrates and hydrazine made ignition at a temperature of $280^{\circ} \mathrm{C}$, and pressure increased from $4 \mathrm{MPa}$ to $5 \mathrm{MPa}$ in the case of the 10.0 at \% Eu-doped sample; this drastic increase is probably what caused pore formation.

In the case of the 10.0 at \% Eu-doped sample, the ignition temperature $\left(280^{\circ} \mathrm{C}\right)$ of the gelatinous blend contained in the beaker inside the reactor was close to the natural ignition temperature $\left(270^{\circ} \mathrm{C}\right)$ of hydrazine. In the PACS stage, the ignition temperature of the 10.0 at \% Eu-doped sample was the highest in comparison with the other Eu-doped samples (see Table 1). Thus, the pressure delivered for this particular case $(10.0$ at $\% \mathrm{Eu})$ was also the highest. The combination of two factors, pressure and temperature, causes a drastic pressure increase, which presumably generated foam-like structures with abundant pores in the 10.0 at \% Eu-doped oxide network sample.

Furthermore, within the 10.0 at \% Eu-doped grains are formed cavities or voids. The cavities are surrounded by thin neighboring walls which increase the amount of active surface exposed to the UV light $(395 \mathrm{~nm})$. These thin walls readily absorb and transmit light, making available the excitation energy. This feature facilitates energy transfer to the luminescent centers, in this case, to the $\mathrm{Eu}^{3+}$ ion which receives the energy directly from the UV light.

$\mathrm{EuAlO}_{3}: \mathrm{Eu}^{2+}$ green phosphor was obtained by the RIRO processing technique. When the 10.0 at \% Eu-doped sample was reduced, the orthorhombic phase was preserved. The 
porosity of the material promoted $\mathrm{NH}_{3}$ diffusion during the RIRO process; subsequently, the decomposition of the $\mathrm{NH}_{3}$ facilitated the reduction of the $\mathrm{Eu}^{3+}$ to $\mathrm{Eu}^{2+}$ ions in the powder. The complete reduction at the surface of the grains increased the luminescent intensity of the green-emitting powder. As mentioned, after the RIRO process, the 10.0 at $\%$ Eu-doped sample showed a broadband emission located at $500 \mathrm{~nm}$ (green).

The 10.0 at \% Eu-doped sample synthesized by PACS produced a red-emitting material, and after RIRO, a highly efficient green-emitting phosphor is obtained. The green phosphor showed a near UV-blue broadband PL excitation (300-450 nm). This near UV-blue excitable phosphor would be a desirable component for the construction of the WLEDs consisting of InGaN chip coated with triphosphor $[5,14]$.

The match of the excitation band of this green phosphor with the emission lines produced by the InGaN diode is very favorable for applications in solid-state white lamps. In this context, this phosphor is a promising candidate to complement the green spectral component of WLEDs composed of a UV-InGaN chip coated with phosphors. Quantum efficiency studies are under progress and will be reported in a future paper in order to further contribute to the technological viability of these phosphors in solid-state white-emitting devices.

\section{Conclusions}

Luminescent powders of europium aluminates $(x=1.5-15.0$ at $\%$ of Eu concentrations) with green emission were successfully produced by pressure-assisted combustion synthesis (PACS). The 10.0 at \% Eu concentration showed the highest luminescence intensity. For this sample, the red emission $(\lambda=616 \mathrm{~nm})$ was also detected under UV excitation of $\lambda=$ $395 \mathrm{~nm}$. The diffusion of $\mathrm{NH}_{3}$ was favored by the porosity in the 10.0 at \% Eu-doped sample. Moreover, after treatment in a reducing atmosphere, a green luminescent powder with high intensity emission was obtained by exciting with UV radiation of $\lambda=398 \mathrm{~nm}$. Due to its high luminescence, it may be concluded that the 10.0 at \% Eu-doped sample exhibits promising optical properties for applications as phosphors in devices coupled to solid-state UV diodes for the development of white-emitting lamps.

\section{Acknowledgments}

The authors are grateful for the technical assistance provided by E. Aparicio, M. Sainz, F. Ruíz, I. Gradilla, J. A. Díaz, V. García, P. Casillas, E. Flores, D. Domínguez, J. Peralta, J. Palomares and M. Sc. Isabel Pérez M. for revising the English version of the manuscript. We acknowledge the financial support from CONACYT (Grant no. 100555) and DGAPA UNAM (Grant IN-114010).

\section{References}

[1] J. R. Oh, S. H. Cho, Y. H. Lee, and Y. R. Do, "Lowering color temperature of $\mathrm{Y}_{3} \mathrm{Al}_{5} \mathrm{O}_{12}: \mathrm{Ce}^{3+}$ white light emitting diodes using reddish light-recycling filter," Electrochemical and SolidState Letters, vol. 13, no. 1, pp. J5-J7, 2010.

[2] S. H. Lee, H. Y. Koo, S. M. Lee, and Y. C. Kang, "Characteristics of $\mathrm{Y}_{3} \mathrm{Al}_{5} \mathrm{O}_{12}$ :Ce phosphor powders prepared by spray pyrolysis from ethylenediaminetetraacetic acid solution," Ceramics International, vol. 36, no. 2, pp. 611-615, 2010.

[3] T. Taguchi, "Present status of white LED lighting technologies in Japan," Journal of Light and Vision Environment, vol. 27, no. 3, pp. 131-139, 2003.

[4] J. S. Kim, P. E. Jeon, Y. H. Park, J. C. Choi, and H. L. Park, "White-light generation through ultraviolet-emitting diode and white-emitting phosphor," Applied Physics Letters, vol. 85, no. 17, pp. 3696-3698, 2004.

[5] A. H. Kitai, "Oxide phosphor and dielectric thin films for electroluminescent devices," Thin Solid Films, vol. 445, no. 1, pp. 367-376, 2003.

[6] S. Pimputkar, J. S. Speck, S. P. Denbaars, and S. Nakamura, "Prospects for LED lighting," Nature Photonics, vol. 3, no. 4, pp. 180-182, 2009.

[7] K. Y. Jung, C. H. Lee, and Y. C. Kang, "Effect of surface area and crystallite size on luminescent intensity of $\mathrm{Y}_{2} \mathrm{O}_{3}$ :Eu phosphor prepared by spray pyrolysis," Materials Letters, vol. 59, no. 1920, pp. 2451-2456, 2005.

[8] G. A. Hirata, F. E. Ramos, and J. McKittrick, "Development of luminescent materials with strong UV-blue absorption," Optical Materials, vol. 27, no. 7, pp. 1301-1304, 2005.

[9] G. Schierning, M. Batentschuk, A. Osvet, A. Stiegelschmitt, and A. Winnacker, "The influence of lattice defects on fluorescence and phosphorescence in the europium aluminate $\mathrm{EuAl}_{2} \mathrm{O}_{4}$," vol. 2, no. 1, pp. 109-112.

[10] Y. Zorenko, V. Gorbenko, M. Grinberg, R. Turos-Matysiak, and B. Kukliński, "High-pressure luminescence spectroscopy of $\mathrm{EuAl}_{2} \mathrm{O}_{4}$ phosphor," Radiation Measurements, vol. 42, no. 4-5, pp. 652-656, 2007.

[11] O. Ozuna, G. A. Hirata, and J. McKittrick, "Luminescence enhancement in $\mathrm{Eu}^{3+}$-doped $\alpha$ - and $\gamma-\mathrm{Al}_{2} \mathrm{O}_{3}$ produced by pressure-assisted low-temperature combustion synthesis," Applied Physics Letters, vol. 84, no. 8, pp. 1296-1298, 2004.

[12] N. Rakov and G. S. Maciel, "Photoluminescence analysis of $\alpha-\mathrm{Al}_{2} \mathrm{O}_{3}$ powders doped with $\mathrm{Eu}^{3+}$ and $\mathrm{Eu}^{2+}$ ions," Journal of Luminescence, vol. 127, no. 2, pp. 703-706, 2007.

[13] S. Geller and V. Bala, "Crystallographic studies of perovskitelike compounds. II. Rare earth alluminates," Acta Crystalographica, vol. 9, no. 1, pp. 1019-1025, 1956.

[14] A. Kitai, Luminescent Materials and Applications, chapter 2, 3, John Wiley \& Sons, New York, NY, USA, 2008.

[15] G. Blasse and B. C. Grabmaier, Luminescent Materials, chapter 2, Springler, Berlin, Germany, 1994.

[16] L. Chonghe, C. K. S. Kitty, and W. Ping, "Formability of $\mathrm{ABO}_{3}$ perovskites," Journal of Alloys and Compounds, vol. 372, no. 12, pp. 40-48, 2004.

[17] G. A. Hirata, E. J. Bosze, and J. Mckittrick, "Development of nanostructured $\mathrm{EuAl}_{2} \mathrm{O}_{4}$ phosphors with strong long-UV excitation," Journal of Nanoscience and Nanotechnology, vol. 8, no. 12, pp. 6461-6465, 2008.

[18] C. E. Rodriguez-Garcia, N. Perea-Lopez, G. A. Hirata, and S. P. DenBaars, "Red-emitting $\mathrm{SrIn}_{2} \mathrm{O}_{4}: \mathrm{Eu}^{3+}$ phosphor powders for applications in solid state white lamps," Journal of Physics D: Applied Physics, vol. 41, no. 9, Article ID 092005, 2008.

[19] O. V. Al'myasheva, E. N. Korytkova, A. V. Maslov, and V. V. Gusarov, "Preparation of nanocrystalline alumina under hydrothermal conditions," Inorganic Materials, vol. 41, no. 5, pp. 460-467, 2005. 
[20] B. J. Scott, G. Wirnsberger, and G. D. Stucky, "Mesoporous and mesostructured materials for optical applications," Chemistry of Materials, vol. 13, no. 10, pp. 3140-3150, 2001.

[21] S. Shionoya and W. M. Yen, Phosphor Handbook, chapter 2, CRC Press, Tokio, Japan, 1999.

[22] F. Gu, C. Z. Li, and H. B. Jiang, "Combustion synthesis and photoluminescence of $\mathrm{MgO}: \mathrm{Eu}^{3+}$ nanocrystals with $\mathrm{Li}^{+}$ addition," Journal of Crystal Growth, vol. 289, no. 1, pp. 400404, 2006.

[23] A. Dulda, D. Sujo, L. S. Pu, T. Masaki, and D. H. Yoon, "New synthesis technology for high efficiency Eu: $\mathrm{YV}_{1-x} \mathrm{P}_{x} \mathrm{O}_{4}$ nanophosphor," Journal of Ceramic Society of Japan, vol. 118, no. 7, pp. 568-570, 2010. 

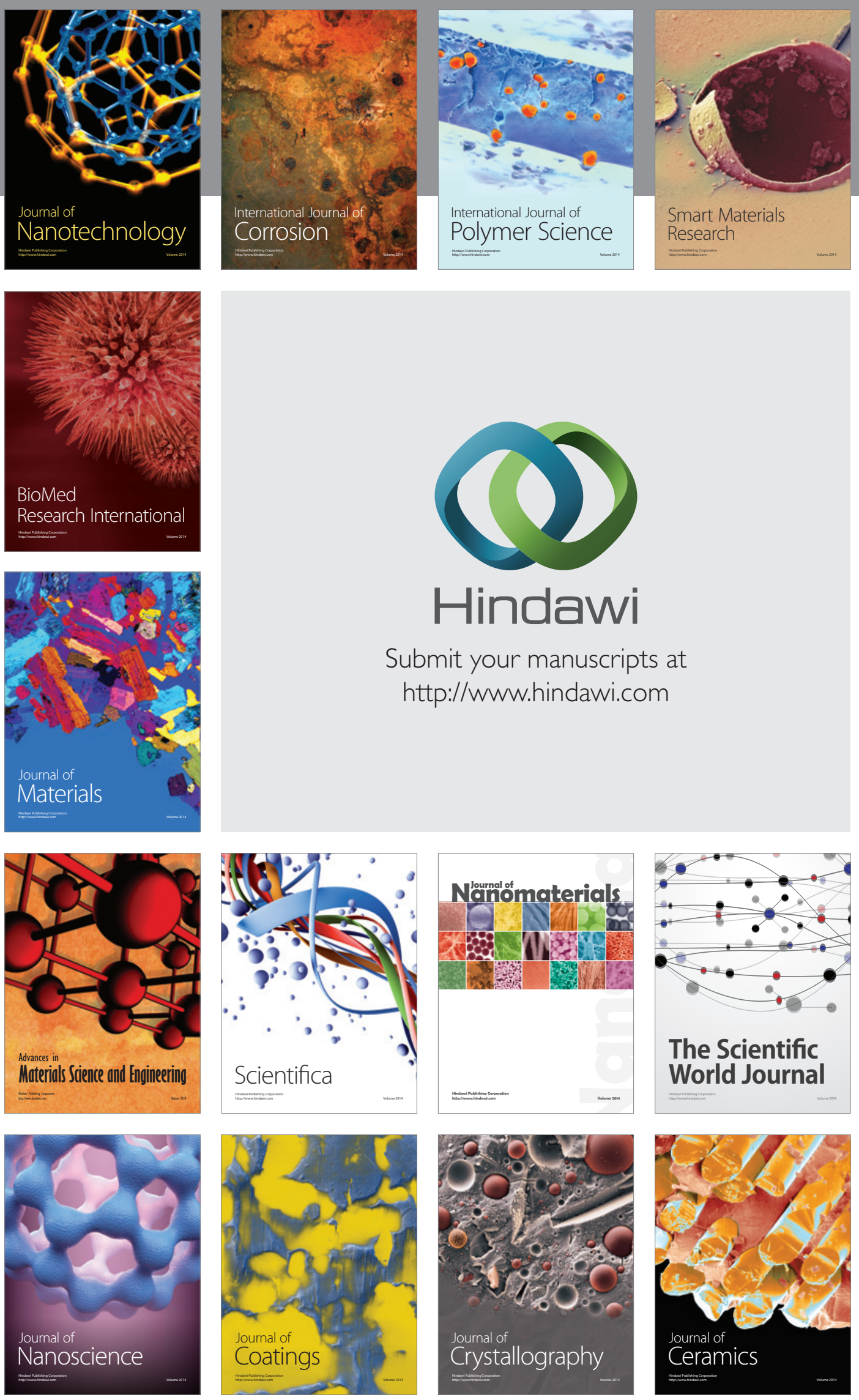

The Scientific World Journal

Submit your manuscripts at

http://www.hindawi.com

\section{World Journal}

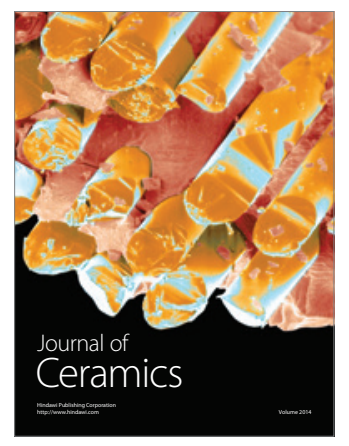

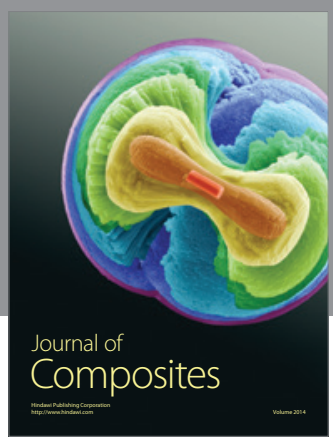
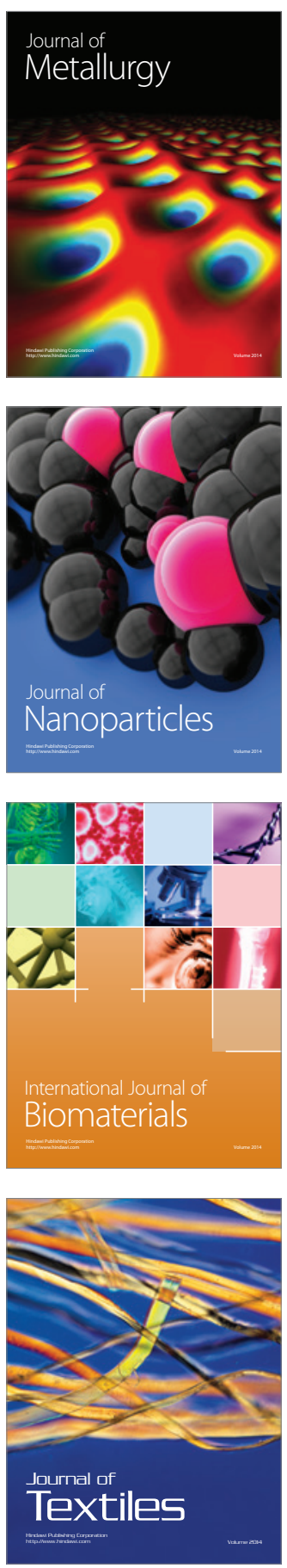